\title{
Maturity Indices for Pigeonpeas
}

\section{F. Sánchez-Nieva, M. M. Cancel, and J. R. Benero ${ }^{1}$}

\section{INTRODUCTION}

Pigeonpeas (Cajan cajan L.) are grown extensively in Puerto Rico both for the fresh market and for canning. For canning operations, the pigeonpeas are purchased on a weight basis, and no objective or subjective quality indices are used to grade the raw product. As a result, the raw material entering the canneries varies in maturity from tender green to fully mature peas which makes it almost impossible to obtain uniform quality in the canned product. In order to improve the quality of the pack, it will be necessary that canners purchase the raw peas on a quality, rather than on a weight basis. To achieve this, it is necessary to establish suitable maturity indices for measuring the quality of the raw peas and to ascertain their suitability for canning.

No information has been published on the use of objective measurements to determine the maturity of pigeonpeas. However, many methods are available for measuring the maturity of peas (Pisum sativum L.) and field peas (Vigna sinensis). Makower has reviewed $(1)^{2}$ most of the tests in use to measure the maturity of peas. Of the several methods proposed, tenderometer readings, specific gravity, alcohol-insoluble solids, total solids, and starch content seem to be the most reliable. More recently Malcolm et al. (2) studied the suitability of these indices to measure the maturity of field peas obtaining a significant correlation between the stage of maturity and the moisture and alcohol-insoluble solids content, starch, resistance to puncturing by a penetrometer, and the percentage juice expressible by pressure.

It was assumed that pigeonpeas would follow a similar pattern of development to peas and field peas and therefore, similar indices could be used to measure the maturity. Consequently, the changes in starch, alcoholinsoluble solids, total solids, total sugars, specific gravity, and soluble-solid content during the development of the pigeonpea were studied.

1 Respectively, Technical Director, Research Assistant in Chemistry, and Assistant Chemist, Food Technology Laboratory, Agricultural Experiment Station, University of Puerto Rico, Rio Piedras, P.R. The authors wish to express their gratitute to other members of the staff of the Food Technology Laboratory for the assistance and cooperation during the course of this study, and to Associate Director B. G. Capó for assistance given in the statistical interpretation of the data. Special recognition is given to $\mathbf{R}$. Abrams who was in charge of the experimental plantings used in this work.

2 Italic numbers in parentheses refer to Literature Cited, p. 69. 


\section{MATERIALS AND METHODS}

\section{SAMPLING}

In the early part of this work, pigeonpeas of the "Saragateado" variety were harvested at different stages of development. Since the pigeonpeas increase in size during ripening, the fullness of the pods was used as a guide for harvesting according to the stage of development. The pods were shelled by hand and the peas grouped according to size. It was observed that the intensity of the green pigment could be used as index of maturity, as the green pigment slowly disappears during ripening. The peas were further subdivided into groups representing different stages of development as judged by the intensity of the green pigment.

Later, pigeonpeas of the Saragateado variety were harvested at different stages of development as follows: A plot of approximately 2.3 acres containing 4,148 trees was divided into 18 rows each containing about 230 trees. The rows were randomized for sampling. When the peas reached the stage of development where fully developed peas with intense green pigment were more abundant, the first two rows were harvested, all pods being picked, irrespective of the stage of development. Two rows selected at random were then harvested at intervals of $3,6,9,12,15,20,22$, and 27 days after the first harvest. The pods from each picking were shelled by row in a Sinclair-Scott pilot-plant huller with a capacity of approximately 500 pounds of pods per hour. Representative samples of the shelled peas were taken for analysis. The numbers of undeveloped, fully developed, ripe, overripe, and dry peas were determined by count in each sample.

\section{ANALYTICAL METHODS}

Starch determination: Starch was determined by the procedure described by Carter and Neubert $(3)$ for the determination of starch in apples. One hundred grams of pigeonpeas are made into a slurry with $100 \mathrm{ml}$. of water in a Waring Blendor. To 7-9 gm. of the slurry in a 50-ml. beaker, $20 \mathrm{ml}$. of 7.8 $\mathrm{N}$. $\mathrm{HClO}_{4}$ are slowly added with constant stirring. After standing for $10 \mathrm{~min}-$ utes at room temperature, the mixture is transferred to a 1000 -ml. volumetric flask and made to volume with distilled water, then filtered through No. 4 Whatman paper. Five milliliters of the filtered solution are transferred to a 100 -ml. volumetric flask, $1 \mathrm{ml}$. of 5-percent $\mathrm{KI}$ sol. and $1 \mathrm{ml}$. of $0.1 \mathrm{~N} . \mathrm{KIO}_{3}$ solution are added and the mixture is let to stand 5 minutes to develop color, and then completed to volume. Percentage transmittance is read in a Spectronic 20 colorimeter at $620 \mu$, with the instrument adjusted to 100 with a blank prepared in the same way as the sample, but decolorized by the addition of two drops of $0.16 \mathrm{~N}$. sodium thiosulfate. The percentage of starch is determined from a curve prepared from the spectrophotometric 
readings of known concentrations of starch isolated from pigeonpeas by the procedure described by Nielsen (4).

Alcohol-insoluble solids: Alcohol-insoluble solids were determined by the A.O.A.C. procedure (5). The sample for analysis was prepared by grinding in a mortar a $50-\mathrm{gm}$. sample with $50 \mathrm{gm}$. of sand. About $30 \mathrm{gm}$. of this preparation are transferred to a $600-\mathrm{ml}$. beaker and extracted for 30 minutes with 80-percent alcohol, at gentle boiling. After the extraction is complete, the sample is filtered, the solids are washed with alcohol until the filtrate is free of coloring matter, and the washed solids are transferred to an aluminum dish and dried at $100^{\circ} \mathrm{C}$. for 2 hours.

Total solids: The total solids and moisture were determined by the A.O.A.C. procedures (6). A representative sample of pigeonpeas is ground in a mortar, and 10-15 gm. are weighed into an aluminum dish and dried to constant weight under vacuum at $70^{\circ} \mathrm{C}$.

Specific gravity: Specific gravity was measured by the method of Jodidi (7) modified as follows: The volume occupied by a $50-$ to $100-\mathrm{gm}$. sample of pigeonpeas was determined from the water displaced when the sample was added to a known volume of water in a $250-\mathrm{ml}$. cylinder.

Soluble solids: Brix; a known weight of pigeonpeas was dispersed in a known weight of water in a Waring Blendor. Soluble solids expressed as Brix were determined by the use of an Abbee refractometer at room temperature $\left(27^{\circ} \mathrm{C}\right.$.) on a clear filtrate from the prepared dispersion. Solublesolid contents were calculated to the original weight of the raw peas.

Total sugars as invert: Total sugars as invert were determined by the A.O.A.C. procedure (8). Fifty grams of pigeonpeas are made into a slurry with $50 \mathrm{gm}$. water in a Waring Blendor. Thirty grams of the slurry are weighed into a 250-ml. volumetric flask, and neutralized with $\mathrm{CaCO}_{3}$. One hundred and fifteen milliliters of 50-percent alcohol are added and the solution is boiled on steam for 1 hour, using a small funnel in the neck of the flask to condense the vapors. The resulting solution is cooled and allowed to stand overnight. Neutral 95-percent alcohol to complete the volume is added, the mixture is well mixed and allowed to settle, and filtered through rapid-filtering filter paper. Two hundred milliliters of the filtrate are transferred into a 400-ml. beaker and evaporated on a steam bath to $20-30 \mathrm{ml}$. The solution is transferred to a $100-\mathrm{ml}$. volumetric flask, enough saturated neutral lead acetate solution is added to produce a flocculent precipitate, it is allowed to stand $\mathbf{1 5}$ minutes, diluted to mark with distilled water, and filtered. The filtrate is deleaded with $\mathrm{Na}_{2} \mathrm{CO}_{3}$ and filtered. Fifty milliliters of the prepared solution are inverted with $5 \mathrm{ml}$. of concentrated $\mathrm{HCl}$ at room temperature, which generally takes about 18 hours. Reducing sugars were determined after inversion by the Munson and Walker procedure ( 8$)$. 


\section{RESULTS AND DISCUSSION}

The average values for starch and alcohol-insoluble solids, specific gravity, and total solids of pigeonpeas at different stages of development, as judged by the size of the peas and the intensity of the green pigment, are

TABLE 1.-Starch, alcohol-insoluble solids, total solids (percent), and specific gravity of pigeonpeas at different stages of development

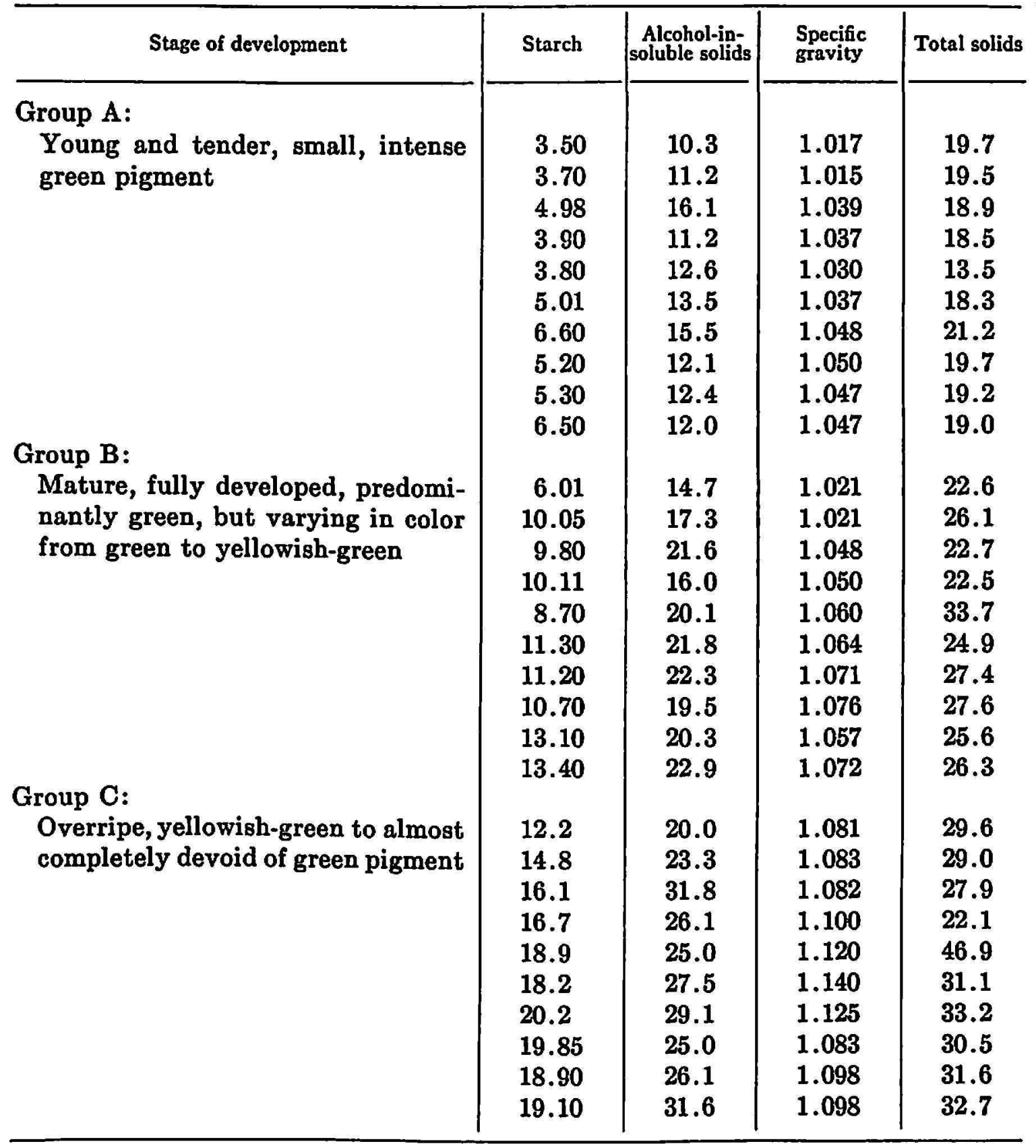

given in table 1. Results of the statistical analyses of these data are shown in table 2; these show that the starch, the alcohol-insoluble solid content, the specific gravity, and the total solids increased as the pigeonpeas mature. Significant differences in starch, alcohol-insoluble solids, and total solids 
were found among the three groups studied. A significant difference was found in the specific gravity between groups $\mathrm{A}$ and $\mathrm{C}$, and between groups $B$ and $C$, but not between groups $A$ and $B$.

These results indicate that the starch, alcohol-insoluble solids, and total solids of pigeonpeas are adequate objective indices of maturity, while the specific gravity is not too reliable. The fact that the specific gravity in-

TABLE 2.-Statistical analysis of data given in table 1

\begin{tabular}{|c|c|c|c|c|c|c|}
\hline \multirow{2}{*}{ Item } & \multicolumn{3}{|c|}{ Mean values for groups- } & \multicolumn{2}{|c|}{$\begin{array}{c}\text { Least significant } \\
\text { difference betwreen } \\
\text { two means at- }\end{array}$} & \multirow{2}{*}{ Remarks } \\
\hline & A & & c & 5 percent & 1 percent & \\
\hline Percentage starch & 4.849 & 10.482 & 17.495 & 2.61 & 3.52 & $\begin{array}{l}\text { Significant difference be- } \\
\text { tween groups at } 1 \text { per- } \\
\text { cent } P \text {. }\end{array}$ \\
\hline $\begin{array}{l}\text { Percentage alco- } \\
\text { hol-insoluble } \\
\text { solids }\end{array}$ & 12.69 & 19.65 & 26.55 & 3.81 & 5.15 & Do. \\
\hline Specific gravity & 1.0367 & 1.0530 & 1.101 & .02290 & .03092 & $\begin{array}{l}\text { Significant difference be- } \\
\text { tween groups } A \text { and } C \\
\text { and } B \text { and } C \text { at } 1 \text { per- } \\
\text { cent } P \text {. No significant } \\
\text { difference between } \\
\text { groups } A \text { and } B \text {. }\end{array}$ \\
\hline Total solids & 18.7 & 25.95 & 32.09 & 5.047 & 6.816 & $\begin{array}{l}\text { Significant difference be- } \\
\text { tween groups } A \text { and } B \\
\text { and } A \text { and } C \text { at } 1 \text { percent } \\
P \text {. Significant difference } \\
\text { between group } B \text { and } C \\
\text { at } 5 \text { percent } P \text {. }\end{array}$ \\
\hline
\end{tabular}

creased as the pea matured led us to regard these results with suspicion. It is probable that the failure to obtain a significant difference between groups A and B was attributable to experimental error, and to the lack of precision of the method employed for measuring the specific gravity. Since the specific gravity determination is made by measuring the volume of water displaced by a known weight of pigeonpeas, the presence of air bubbles and moisture in the sample affects the determination. Young, tender peas are usually wet and, when immersed in water, many air bubbles can be seen adhering to their surface, which may lead to a fairly great experi- 
mental error when the method of volume displacement is used to measure the specific gravity at this stage of development.

Since pigeonpeas possess undetermined fruiting characteristics it is common to find peas at all stages of development, even on the same shrub. During harvesting, it is almost impossible to pick only peas at a certain stage of development, and, consequently, it is to be expected that the commercial produce will be a heterogeneous mixture of peas at many stages of development. Objective indices to be used for measuring the maturity of pigeonpeas should be capable of indicating differences between the heterogeneous mixtures at different intervals throughout the crop. If this is not possible, the use of objective maturity indices already discussed will be useless in the commercial harvesting of the crop.

TABL: 3.-Percentages of pigeonpeas tested which were at different stages of derelopment

\begin{tabular}{|c|c|c|c|c|c|c|c|c|c|}
\hline \multirow{2}{*}{ Type of peas } & \multicolumn{9}{|c|}{ Percentage at indicated time interval between harvest in days } \\
\hline & 0 & 3 & 6 & 9 & 12 & 15 & 20 & 22 & 27 \\
\hline Small and undeveloped & 25.5 & 9.5 & 16.5 & 10.5 & 16.5 & 14 & $\mathbf{5}$ & 14 & 7 \\
\hline Large, mature, green & 72 & 90 & 78 & 80 & $6 \mathbf{7}$ & 62 & 49 & 48.5 & 44 \\
\hline Large, ripe, yellow color & 0 & .5 & 2 & 7 & 10.5 & 13 & 24 & 13.5 & 14.5 \\
\hline Dry & 2.5 & $\mathbf{0}:$ & 3.5 & 2.5 & 6 & 11 & 22 & 24 & 34.5 \\
\hline
\end{tabular}

In order to test whether the objective indices already proved to show difference in maturity are suitable for indicating the maturity of the peas when harvested commercially, the pigeonpeas from 18 randomized plots were harvested at internals of $3,6,9,12,15,20,22$ and 27 days after the first picking, as described under "Sampling." In order to have a sample of pigeonpeas representing the whole plantation, pickers were instructed to pick all pods irrespective of the stage of development. When shelled, the sample consisted of a mixture of young tender peas, developed peas with intense green pigment, turning peas with greenish-yellow color, ripe peas completely devoid of green pigment, and dry peas. Although it is true that dry pods are not picked in commercial practice, it was decided to pick these as well in order to reduce any hias which might have been introduced by selective picking.

The number of peas at each stage of development for each harvest is given in table 3. It should be noted that the pereentage of undeveloped peas was much higher in the first picking than in the last, while the percentage of yellow and dry peas increased from the 9-day harvest interval to the last picking. I'sing the intensity of the green pigment as a visual 


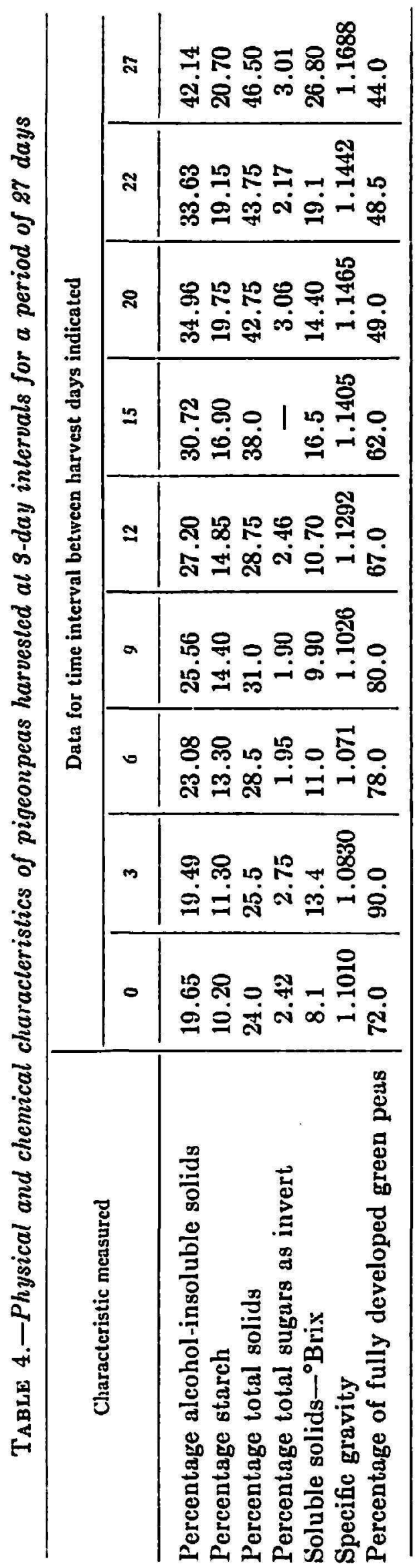


index of maturity, it can be concluded that the number of ripe peas, including the dry ones, increases with crop length. It is reasonable to expect that the starch and alcohol-insoluble solids, the total solids, and the specific gravity will increase progressively from the first to the last crop, and if these measures are adequate maturity indices, it should be possible to sbtain a significant correlation between any of these values and the intensity of the green pigment.

The values obtained for starch, alcohol-insoluble solids, total solids, specific gravity, total sugar as invert, and the soluble solids as Brix, are given in table 4. It will be observed that, as expected, there is an approximately progressive increase in the starch, alcohol-insoluble solids, total solids, and specific gravity from the first to the last crop. It should also

TABLE 5.-Correlation between percentage of fully developed green pigeonpeas and proposed objective indices

\begin{tabular}{|c|c|c|c|c|}
\hline \multirow{2}{*}{ Index } & \multirow{2}{*}{$\begin{array}{l}\text { Range of values } \\
\text { measured }\end{array}$} & \multicolumn{3}{|c|}{ Coefficient of correlation value } \\
\hline & & Experimental & $\begin{array}{l}\text { At } 5 \text {-percent } \\
\text { level }\end{array}$ & $\begin{array}{c}\text { At 1-percent } \\
\text { level }\end{array}$ \\
\hline $\begin{array}{l}\text { Percentage alcohol-insoluble } \\
\text { solids }\end{array}$ & $19.65-42.14$ & -0.9143 & 0.666 & 0.798 \\
\hline Percentage starch & $10.20-20.70$ & -.9458 & .666 & .798 \\
\hline Percentage total solids & $72.00-44.0$ & -.9043 & .666 & .798 \\
\hline $\begin{array}{l}\text { Percentage total sugar as in- } \\
\text { vert }\end{array}$ & $2.42-3.06$ & -.4577 & .707 & .834 \\
\hline Soluble solids- ${ }^{\circ}$ Brix & $8.1-26.8$ & -.0939 & .666 & .798 \\
\hline Specific gravity & $1.071-1.1688$ & -.9234 & .666 & .798 \\
\hline
\end{tabular}

be noted that the change in the total reducing sugars and the soluble solids followed no definite pattern.

The correlation coefficients obtained from correlating the values of the proposed objective indices and the percentage of fully developed green peas are given in table 5 . Correlation coefficients significant at 1-percent $P$. were obtained for starch, alcohol-insoluble solids, total solids, and specific gravity. No significant correlation was obtained between total sugars as invert and percentage of green peas, nor between soluble solids or degree Brix and green peas.

As may be seen from the values in tables 4 and 5 , total solids, percentage of starch, alcohol-insoluble solids, and specific gravity, are good indices of maturity for pigeonpeas. For precise laboratory-control work the alcoholinsoluble-solids determination, although time-consuming, is to be preferred, as it is more consistent, and reproducible results can be obtained. Although the starch content is a good indication of maturity, the method is subject 
to many errors which may lead to inconsistent results. Extreme care must be taken to completely solubilize the starch and avoid hydrolysis; otherwise, low starch values may be obtained.

Since total solids and moisture are intimately related, moisture content may be used instead of using total solids as a maturity index. In this case, it should be remembered that the moisture content of pigeonpeas varies inversely with maturity, beging higher for tender and lower for mature peas. With the new infrared moisture-determination balances available, a moisture determination can be performed in a relatively short time, so the moisture content may prove to be an adequate index for routine determinations. Malcolm et al. (2) compared the A.O.A.C. vacuum-oven method with the infrared method for the determination of moisture in field peas, and concluded that the latter was less variable when replicate samples were compared. Similar results were obtained in this work when the A.O.A.C. vacuum-oven method was compared with the infrared method, using the infrared moisture-determination balance.

The specific-gravity determination, although less precise than the others, may be used as a field test for the determination of the maturity of pigeonpeas. In using this method it should be remembered that moisture in the sample and air under the skin, as well as the size of the sample, may introduce a large error which can result in failure to detect small differences in specific gravity.

\section{SLMMARY}

When pigeonpeas mature, there is an increase in the starch, alcoholinsoluble solids, and total-solids contents, and in the specific gravity, and a decrease in the intensity of the green pigment. A high correlation was obtained between the intensity of the green pigment and starch, alcoholinsoluble solids, total solids, and specific gravity. A high correlation was also obtained between the number of green peas in a heterogeneous sample containing peas at different stages of development and all of the abovementioned measures. Any of these measurements can be used ats a maturity index for pigeonpeas. Since the moisture content is directly related to the total solids, moisture can also be used as a suitable and reliable maturity index.

\section{RESUMEN}

Cuando el gandur madura, su contenido de almidón, sus sólidos insolubles en alcohol, sus sólidos totales y su gravedad específica aumentan gradualmente, mientras que el pigmento verde disminuye. Se ha encontrido cue existe una correlación significativa ent re la intensidad del pigmento verde $y$ cada una de las condiciones del gramo antes indicadas. Ha sido posible 
también establecer uni correlación, altamente significativa, entre el número de granos verdes en una muestral heterogénea que contiene gandures en distintas etapas de desarrollo, con el contenido de almiclón, los sólidos solubles en alcohol, los sólidos totales y la gravedad específica. Se ha demostrado además, que cualquiera de estas medidas puede us.rse como índice de madurez para indicalr el estado de desarrollo del grano. Como el contenido de humedad y los sólidos totales están íntimamente relacionados, la primeru de eslas medidas puede us.urse también como un índice de madurez.

\section{LITERATURE CI'PED}

1. Makower, R. U., Methods of measuring the tenderness and maturity of processed peas, Food 'l'echnol. 4 403-8 1950.

2. Malcolm, H. R., Powers, J. J., López, A., Pratt, 1)., ()bjective measurements of the maturity of raw canned field peas, Food Technol. 10 +63-9, 1956.

3. Carter, (i. H., Neubert, A. M., Rapid determination of starch in apples, Agr. \& Food Chem. 2 1070-2, 1954.

4. Nielsen, J. P., Rapid determination of starth, Ind. Eng. ('hem. An. Ed. 15 176-9, 1953.

5. Official Methods of Analysis, Assn. of Agr. Chem., Washington, 1). C., Sth ed., 572,1955 .

6. Official Methods of Analysis, Assn. of Agr. Chem., Washington, D. C., Sth ed., $343,1955$.

7. Jodidi, S. I., Maturity test for peats, Canning .1 ge $19297,336,1938$.

8. Official Methods of Analysis, Assn. of Agr. Chem., Washington, 1). C., 8th ed., $545,1955$.

9. Official Methods of Analysis, Assn. of Agr. Chem., Wishington, D. C., 8th ed., 410-1, 1955. 